\title{
Intramyocellular lipids of muscle type in athletes of different sport disciplines
}

This article was published in the following Dove Press journal:

Open Access Journal of Sports Medicine

II July 2017

Number of times this article has been viewed

\author{
Yoshinao Nakagawa' \\ Masaaki Hattori ${ }^{2}$ \\ 'Human Performance Lab, Otaru \\ University, Otaru, Hokkaido, \\ ${ }^{2}$ Department of Community \\ Development, Tokai University, \\ Sapporo, Japan
}

\begin{abstract}
The present study used magnetic resonance spectroscopy ( $\left.{ }^{1} \mathrm{H}-\mathrm{MRS}\right)$ to examine quantitative differences in intramyocellular lipid (IMCL) contents in various muscle types at rest for individual athletes from different sport disciplines. Five groups consisting of sprinters, alpine skiers, cross-country skiers, endurance runners and untrained healthy male subjects volunteered for this study. Data were acquired using ${ }^{1} \mathrm{H}-\mathrm{MRS}$ from the tibialis anterior (TA), medial gastrocnemius (MG) and soleus (SOL) muscles. No significant difference was found in the cross-sectional area (CSA) of the TA, MG and SOL muscles, whereas the CSA of subcutaneous fat was significantly lower $(p<0.01)$ for each athlete group compared with untrained subjects. In both TA and MG, IMCL concentrations in endurance runners were significantly higher than those of alpine skiers $(p<0.01)$, sprinters $(p<0.01)$ and untrained subjects $(p<0.05)$. The IMCL concentrations in TA and MG of cross-country skiers were significantly higher than those of alpine skiers $(p<0.05)$ and sprinters (TA, $p<0.01$; MG, $p<0.05)$. There was no significant difference in the IMCL concentrations of TA and MG between alpine skiers or sprinters and untrained subjects. The IMCL concentration in SOL was significantly greater in endurance runners and showed no difference in cross-country skiers compared with that in alpine skiers and sprinters. There was no significant difference in the IMCL concentration of SOL between athletes and untrained subjects. These results suggest that differences in IMCL contents stored in various muscle types for athletes at rest are associated with the muscle cellular adaptation for differences in the type of exercise training and/or muscle fiber composition.
\end{abstract}

Keywords: IMCL, alpine ski, skeletal muscle, sports

\section{Introduction}

Fat throughout the body is mainly stored as triacylglycerol (TG) in subcutaneous adipose tissue and deep visceral adipose tissue. Smaller quantities of TG are present as lipid droplets in muscle cells (intramyocellular lipid [IMCL]). IMCL is thought to be dynamic and undergoes rapid equilibrium with substrate utilization and supply. In particular, IMCL plays an important role in the energy metabolism of muscle cells. IMCL appears to be influenced by metabolic capacity, as in fiber type composition, and histochemical analysis shows a higher IMCL concentration in type I fibers compared with type II fibers. ${ }^{1}$

Biochemical quantification and histochemical quantification of lipids in biopsy studies have shown that lipid content in vastus lateralis muscle may reflect adaptive response to physical training conditions. ${ }^{2-6}$ Recently, a proton magnetic resonance spectroscopy ( $\left.{ }^{1} \mathrm{H}-\mathrm{MRS}\right)$ method has made it possible to measure IMCL quantitatively and noninvasively in magnetic resonance imaging (MRI)-localized individual
Correspondence: Yoshinao Nakagawa Human Performance Lab, Otaru University, 3-5-2I, Midori, Otaru 047850I, Hokkaido, Japan

Tel/fax +8I I34 2754 I5

Email nak@res.otaru-uc.ac.jp 
muscles in human beings. ${ }^{7,8}$ The distribution of muscle fibers is assumed to be one of the physiologic factors that might influence ${ }^{1} \mathrm{H}$-MRS results. ${ }^{1} \mathrm{H}$-MRS tests have shown that muscle groups with a high type I fiber composition have a higher IMCL content than muscles of type II fiber predominance in intact human beings..$^{9-12}$ Previously, crosssectional ${ }^{1} \mathrm{H}$-MRS studies have compared endurance trained and untrained subjects at rest, ${ }^{13}$ and it was demonstrated that endurance-trained subjects have higher IMCL content in their tibialis anterior (TA) muscle than sedentary men. The little information is available to describe IMCL storage in athletes of different sport disciplines, ${ }^{14}$ especially alpine racing skiers with aerobic and anaerobic capacities. If this adaptive response to endurance training is valid, it should be evident in various muscle types (TA, medial gastrocnemius [MG] and soleus [SOL]) of athletes specializing in various sport disciplines with different energy systems; however, this has not been determined.

The present study was conducted on well-trained athletes, sprint runners, alpine skiers, cross-country skiers and endurance runners. We hypothesized that IMCL content in athletes of predominant aerobic system would be higher than that in anaerobic-trained athletes. Finally, we aimed to evaluate the use of ${ }^{1} \mathrm{H}-\mathrm{MRS}$ as a noninvasive tool to monitor IMCL concentrations in various muscle types at rest for individual athletes of different sport disciplines characterized by anaerobic and/or aerobic capacities and muscle fiber composition.

In the present study, we used ${ }^{1} \mathrm{H}-\mathrm{MRS}$ to noninvasively determine quantitative differences in IMCL content in various muscle types at rest for individual athletes of different sport disciplines characterized by anaerobic and/or aerobic capacities and muscle fiber composition.

\section{Methods}

\section{Subjects}

Thirty-two male volunteers participated in this study. Five groups consisting of sprinters $(n=5)$, alpine skiers $(n=10)$, cross-country skiers $(n=10)$, endurance runners $(n=6)$ and untrained subjects $(n=7)$ volunteered for this study. These athletes in four different sport disciplines with a history of competition over the past years were elite collegiate athletes in Hokkaido. The untrained subjects were chosen from active college students. The subjects were matched for age (Table 1). All subjects were fully informed of the risks and discomfort associated with these experiments before giving their written consent to participate. The study was approved by the local institutional ethical committee of Sapporo Medical
Table I Physical characteristic in athletes of different sport disciplines

\begin{tabular}{lllll}
\hline Group & $\mathbf{n}$ & Age, years & BW, kg & BMI, $\mathbf{~ g g / \mathbf { m } ^ { 2 }}$ \\
\hline Sprinters & 5 & $20.4 \pm 1.9$ & $66.4 \pm 7.2$ & $21.4 \pm 1.1$ \\
Alpine skiers & 10 & $19.8 \pm 2.0$ & $73.0 \pm 7.8^{* *}$ & $24.7 \pm 2.5^{* * . \#}$ \\
Untrained & 7 & $20.4 \pm 1.1$ & $58.3 \pm 6.2$ & $20.0 \pm 1.6$ \\
Cross-country skiers & 10 & $21.7 \pm 2.4$ & $64.4 \pm 2.2$ & $22.2 \pm 1.2$ \\
Endurance runners & 6 & $21.0 \pm 1.4$ & $58.3 \pm 2.3$ & $20.7 \pm 1.0$ \\
\hline
\end{tabular}

Notes: Values are mean $\pm S D . n=n o$ of subjects. ${ }^{*} p<0.01$ vs untrained subjects, " $p<0.05$ vs sprinters.

Abbreviations: BW, body weight; BMI, body mass index.

University. The study conformed to the principles of the Declaration of Helsinki.

\section{'H-MRS and MRI}

Magnetic resonance (MR) images for localization and ${ }^{1} \mathrm{H}$-MRS were acquired using a clinical $1.5 \mathrm{~T}$ whole body scanner system (Signa Horizon LX; GE Medical Systems; Milwaukee, MI, USA). A standard head coil (28 cm diameter) was used for detection. In each examination, subjects lay in a supine position with the right calf placed along the axis of the head coil. Transverse $\mathrm{T}_{1}$-weighted MR images ( $\mathrm{TR} / \mathrm{TE}=300 / 8.5 \mathrm{~ms}$ ) were acquired to determine the placement of the ${ }^{1} \mathrm{H}-\mathrm{MRS}$ voxels, with a slice thickness of $5 \mathrm{~mm}$, $28 \mathrm{~cm}$ field and $512 \times 512$ data matrix. The ${ }^{1} \mathrm{H}-\mathrm{MRS}$ was obtained from TA, MG and SOL muscles at the maximum circumference of the calf. The voxel volume of interest $\left(10 \times 10 \times 10 \mathrm{~mm}^{3}\right)$ within each muscle was centered over each muscle to avoid vascular structures and adipose tissue from subcutaneous fat or fasciae included in the localized region (Figure 1). Localized proton spectra were obtained using a PRESS sequence with TE/TR=30/2000 ms and 128 averages with water suppression. Spectra were processed using the Nuts software package (Acorn NMR Inc., Livermore, CA, USA). Spectra were line broadened and phase and baseline corrected, ${ }^{12}$ and the resonances of interest were line fit at a mixed Lorentzian/Gaussian function. After correction for $\mathrm{T}_{1}$ and $\mathrm{T}_{2}$ relaxation, the quantitation of IMCL content was performed comparing the intensity of $\left(\mathrm{CH}_{2}\right)_{n}$ (methylene) at $1.3 \mathrm{ppm}$ resonance to the water resonance intensity at 4.7 ppm. ${ }^{12}$ IMCL was quantified relative to muscle water by using units of millimoles per kilogram wet weight, assuming tissue density of $1.05 \mathrm{~kg} / \mathrm{L}^{15}$ and the number of $\left(\mathrm{CH}_{2}\right)_{n}$ groups per triglyceride chain for the average triglyceride molecule. ${ }^{16}$

On the day of determining IMCL concentrations by ${ }^{1} \mathrm{H}$-MRS, the subjects were not allowed to do exercise or sports. They ate lunch at 12:00-13:00 $\mathrm{h}$ and thereafter were prohibited to consume any food except water. In the 

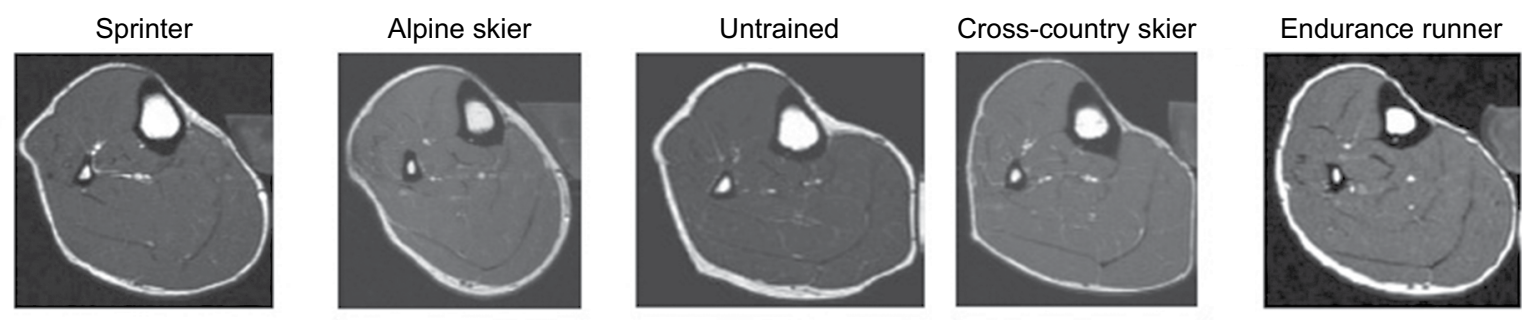

IMCL

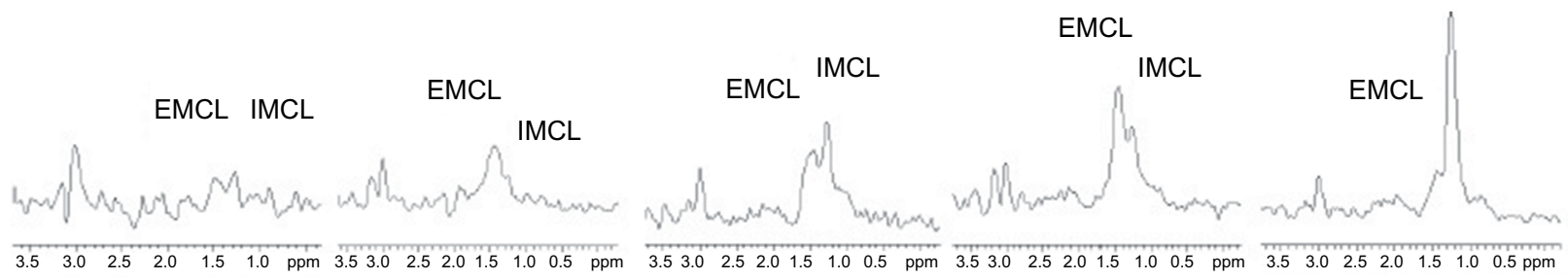

Figure I Typical T,-weighted transverse image of lower leg and localized 'H-MRS of TA in sprinter, alpine skier, untrained subject, cross-country skier and endurance runner. Note: The assignment of the resonance is as follows: EMCL, I.5 Ppm; IMCL, I.3 Ppm.

Abbreviations: 'H-MRS, magnetic resonance spectroscopy; TA, tibialis anterior; EMCL, extramyocellular lipid; IMCL, intramyocellular lipid.

evening, the subjects reported to the laboratory by public transportation. Measurement of IMCL was started at 18:00 h in 5-6 $\mathrm{h}$ postprandial state.

For determination of cross-sectional area (CSA), the MR images were transferred to a personal computer and analyzed using OsiriX software (version 3.3.1, open-source software). The TA, MG and SOL muscles and subcutaneous fat were outlined manually three times for analysis, and CSA was determined as the average of the three analyses. The subcutaneous fat area was calculated as the difference between total segment area and the area on the inner side from the subcutaneous fat.

\section{Statistics}

The results were expressed as mean $\pm \mathrm{SD}$. Statistical analysis among the group was performed by one-way analysis of variance (ANOVA). When a significant $F$ ratio was obtained, post hoc analysis was performed using a Dunnett's multiple comparison test. The level of significance for all comparisons was set at $p<0.05$. All statistical analyses were computed using Prism software (version 4.0; GraphPad Software, Inc., La Jolla, CA, USA).

\section{Results}

Table 2 indicates CSA of TA, MG and SOL muscles and subcutaneous fat among subjects. No significant difference was found in the CSA of TA, MG and SOL muscles, whereas the CSA of subcutaneous fat was significantly lower $(p<0.01)$ for each athlete group compared with untrained subjects.

Figure 2 shows the IMCL concentrations in TA, MG and SOL muscles among athletes of different sport disciplines. The IMCL concentration was high in the order of
Table 2 CSAs of calf muscles in athletes from different sport disciplines

\begin{tabular}{|c|c|c|c|c|}
\hline Group & $\mathrm{TA}, \mathrm{cm}^{2}$ & MG, $\mathbf{c m}^{2}$ & $\begin{array}{l}\text { SOL, } \\
\mathrm{cm}^{2}\end{array}$ & $\begin{array}{l}\text { Subcutaneous } \\
\text { fat, } \mathrm{cm}^{2}\end{array}$ \\
\hline Sprinters & $11.0 \pm 1.7$ & $10.1 \pm 2.9$ & $24.7 \pm 4.2$ & $10.8 \pm 2.7^{*}$ \\
\hline Alpine skiers & $11.1 \pm 1.6$ & $13.3 \pm 3.8$ & $24.8 \pm 4.8$ & $11.1 \pm 3.0 * *$ \\
\hline Untrained & $10.4 \pm 1.6$ & $11.0 \pm 1.5$ & $22.4 \pm 5.6$ & $15.8 \pm 3.0$ \\
\hline $\begin{array}{l}\text { Cross-country } \\
\text { skiers }\end{array}$ & $10.8 \pm 0.7$ & II $.4 \pm 3.3$ & $23.6 \pm 2.8$ & $8.6 \pm 2.0 * *$ \\
\hline $\begin{array}{l}\text { Endurance } \\
\text { runners }\end{array}$ & $10.4 \pm 0.8$ & $11.3 \pm 1.9$ & $23.2 \pm 1.8$ & $9.9 \pm 2.2^{* *}$ \\
\hline
\end{tabular}

Notes: Values are mean \pm SD. $* p<0.05$ and $* * p<0.01$ vs untrained subjects.

Abbreviations: CSA, cross-sectional area; TA, tibialis anterior; MG, medial gastrocnemius; SOL, soleus.

$\mathrm{TA}<\mathrm{MG}<\mathrm{SOL}(p<0.01)$. There was a significant difference among athletes of different sport disciplines (endurance runners $>$ untrained subjects, alpine skiers and sprinters, $p<0.01)$. In both TA and MG, the IMCL concentration of endurance runners was 2.0 times statistically significantly greater than that of untrained subjects $(p<0.05)$ and 2.0-3.0 times significantly greater than that of alpine skiers $(p<0.01)$ and sprinters $(p<0.01)$. The IMCL concentrations in TA and MG of cross-country skiers were significantly higher than those of alpine skiers $(p<0.05)$ and sprinters (TA, $p<0.01$; $\mathrm{MG}, p<0.05)$. In a comparison of alpine skiers or sprinters and untrained subjects, no significant difference in IMCL contents of TA and MG was found. With respect to SOL, IMCL concentration was two times significantly greater in endurance runners and showed no difference in cross-country skiers compared with that of alpine skiers and sprinters. There was no significant difference in the IMCL concentration of SOL between athletes and untrained subjects. 


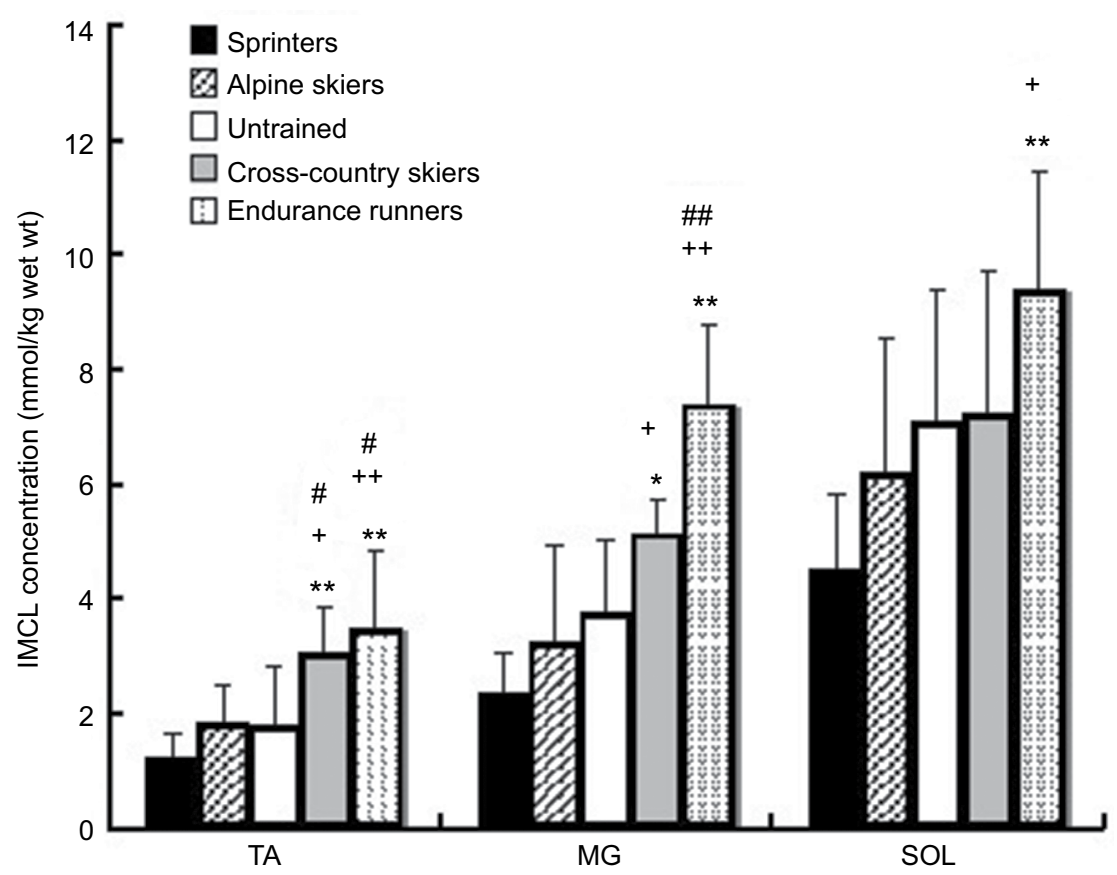

Figure $2 \mathrm{IMCL}$ concentrations of TA, MG and SOL in athletes of four different sport disciplines and untrained subjects.

Notes: Results were expressed as mean \pm SD. Significantly different from sprinters: ${ }^{*} p<0.05$ and ${ }^{* *} p<0.0$ I. Significantly different from alpine skiers: ${ }^{+} p<0.05$ and ${ }^{++} p<0.0$ I. Significantly different from untrained subjects: ${ }^{\#}<<0.05$ and ${ }^{\#} p<0.0$ I.

Abbreviations: IMCL, intramyocellular lipid; TA, tibialis anterior; MG, medial gastrocnemius; SOL, soleus.

\section{Discussion}

This study compared lower leg composition and IMCL concentrations in different muscle types of athletes from various sport disciplines with different energy systems. There were no differences between the groups in the CSA of each muscle. The only significant difference was found in the CSA of subcutaneous fat between athletes and untrained subjects. These results given agree with the results of a previous study using MRI in elite athletes. ${ }^{17}$

Postural muscles, such as SOL and TA, are typically involved in continuous force maintenance, and muscle fiber in these muscles is of great functional significance. Especially, TA is the major dorsiflexor of the ankle with a very homogeneous distribution of activity within muscles. There was a clear predominant of type I fibers $(79.0 \pm 1.6 \%)$ in TA among athletes, ${ }^{18}$ which may contract quickly by walking and physical activity. The IMCL concentrations in TA, MG and SOL examined in the present study were within the range of IMCL concentrations obtained from previous studies using ${ }^{1} \mathrm{H}-\mathrm{MRS} .{ }^{7}, 10,12,15$ The IMCL concentrations in SOL were higher than those in TA and MG. These regional data in athletes and untrained subjects demonstrated that IMCL concentrations in MG and SOL were two- or threefold that the concentration in TA. This is closely associated with the result of previous ${ }^{1} \mathrm{H}-\mathrm{MRS}$ studies that showed a two- or threefold higher IMCL concentration in SOL relative to that in TA., ${ }^{9,10}$
We think that it would be a higher metabolic turnover rate of IMCL in TA than that in MG and SOL.

Several observations have been made concerning muscle fiber type and the possible influence of specific training on fiber composition and metabolic capacity. Successful endurance athletes generally demonstrate a predominance of slow-twitch fibers in the muscle activated in their specific sport. For successful sprint athletes, the fast-twitch muscle fibers predominate. ${ }^{19}$ The fiber type is known to be related to IMCL (triglyceride) concentrations in muscle, with biochemical studies using a needle biopsy technique showing that type I fibers contain a threefold higher lipid content than type II fibers. ${ }^{1}$ Although TA and SOL predominantly had type I fibers (slow twitch, oxidative) and MG had a relatively mixed composition of type I and type II fibers (intermediate muscle), ${ }^{20,21}$ absolute IMCL concentrations in TA in both athletes and untrained subjects were lower than those in MG and SOL. Type I and type IIx fibers of TA are smaller and larger, respectively, than the same type fibers in the SOL. ${ }^{21}$

The larger average fiber size in the SOL compared with TA may speak to the general expectation that loading of slow powerful plantar flexor would be greater than its slow dorsiflexor counterpart. ${ }^{22}$ It is explained by the finding that average fiber succinate dehydrogenase (SDH) activity and fiber-type specific SDH:qATPase*\%CSA, both are used as estimates of fatigue resistance and are lower in TA than 
in SOL. ${ }^{21}$ The results were interpreted to suggest that the magnitude of IMCL storage is more reflective of functional diversity among muscle types than phenotypic expression.

The IMCL level in a given muscle fiber will reflect the opposing effects of oxidation into muscle cells and TG uptake from circulation. ${ }^{23}$ Lipoprotein lipase (LPL) in muscle plays a direct role in IMCL accretion, ${ }^{24}$ and endurance training leads to an increase in LPL activity. ${ }^{25}$ Meanwhile, LPL activity levels in sprinters are equivalent to those found in sedentary individuals and significantly less than those in endurance runners. ${ }^{26}$ Hamilton et $\mathrm{al}^{27}$ found that LPL activity in highintensity running in rats did not change in red muscle or in white muscle not recruited during running and increased in white muscle with a high level of recruitment during running. The increase in LPL activity induced by endurance training could account for the replenishment of the IMCL accumulated in the droplets. ${ }^{23}$ Vock et $\mathrm{al}^{28}$ reported increased contact area between lipid droplets and mitochondria in the muscles of trained pigmy goats and dogs. Hoppeler et $\mathrm{al}^{4}$ found that muscle lipid inclusion was located adjacent to mitochondria in trained men, whereas in sedentary subjects, the same was not observed. In a previous study of human beings, high-intensity endurance training led to an increased volume density of mitochondria in all the fiber types and volume density of IMCL in type II fibers. ${ }^{29}$

\section{Conclusion}

The present data suggest that resting IMCL concentration of muscle type among athletes of different sport disciplines, as assessed noninvasively by ${ }^{1} \mathrm{H}-\mathrm{MRS}$, may reflect the muscle cellular adaptation associated with differences in the type of exercise training.

\section{Acknowledgments}

This work was supported by JSPS KAKENHI Grant Number 17200040. The authors thank the athletes for their participation, as well as Goro Okano, Kuniaki Harada, Ryuji Shirase (Spporo Medical University), and Kazuki Takizawa (Hokkaido University) for their assistance in the data collection.

\section{Disclosure}

The authors report no conflicts of interest in this work.

\section{References}

1. Essen B, Jansson E, Henriksson J, Taylor AW, Saltin B. Metabolic characteristics of fibre types in human skeletal muscle. Acta Physiol Scand. 1975;95(2):153-165.

2. Morgan TE, Short FA, Cobb LA. Effect of long-term exercise on skeletal muscle lipid composition. Am J Physiol. 1969;216(1):82-86.
3. Prince FP, Hikida RS, Hagerman FC, Staron RS, Allen WH. A morphometric analysis of human muscle fibers with relation to fiber types and adaptations to exercise. J Neurol Sci. 1981;49(2):165-179.

4. Hoppeler H, Howald H, Conley K, et al. Endurance training in humans: aerobic capacity and structure of skeletal muscle. J Appl Physiol. 1985;59(2):320-327.

5. Goodpaster BH, He J, Watkins S, Kelley DE. Skeletal muscle lipid content and insulin resistance: evidence for a paradox in endurancetrained athletes. J Clin Endocriol Metab. 2001;86(12):5755-5761.

6. van Loon LJ, Koopman R, Manders R, van der Weegen W, van Kranenburg GP, Keizer H. A Intramyocellular lipid content in type 2 diabetes patients compared with overweight sedentary men and highly trained endurance athletes. Am J Physiol Endocrinol Metab. 2004;287(3):E558-E565.

7. Schick F, Eismann B, Jung WI, Bongers H, Bunse M, Lutz O. Comparison of localized proton NMR signals of skeletal muscle and fat tissue in vivo: two lipid compartments in muscle tissue. Magn Reson Med. 1993;29(2):158-167.

8. Boesch C, Slotboom J, Hoppeler H, Kreis R. In vivo determination of intra-myocellular lipids in human muscle by means of localized ${ }^{1}$ H-MR-spectroscopy. Magn Reson Med. 1997;37(4):484- 493.

9. Rico-Sanz J, Thomas EL, Jekinson G, Mierisova S, Iles R, Bell JD. Diversity in levels of intracellular total creatine and triglycerides in human skeletal muscles observed by ${ }^{1} \mathrm{H}-\mathrm{MRS}$. J Appl Physiol. 1999;87(6):2068-2072.

10. Hwang JH, Pan JW, Heydari S, Hetherington HP, Stein DT. Regional differences in intramyocellular lipids in humans observed by in vivo ${ }^{1} \mathrm{H}-\mathrm{MR}$ spectroscopic imaging. J Appl Physiol. 2001;90(4):1267-1274.

11. Thamer C, Machann J, Bachmann O, et al. Intramyocellular lipids: anthropometric determinants and relationships with maximal aerobic capacity and insulin sensitivity. $J$ Clin Endocrinol Metab. 2003;88(4):1785-1791.

12. Nakagawa Y, Hattori M, Harada K, Shirase R, Bando M, Okano G. Age-related changes in intramyocellular lipid in humans by in vivo ${ }^{1} \mathrm{H}-\mathrm{MR}$ spectroscopy. Gerontology. 2007;53(4):218-223.

13. Decombaz J, Schmitt B, Ith M, et al. Postexercise fat intake repletes intramyocellular lipids but no faster in trained than in sedentary subjects. Am J Physiol Regul Integr Comp Physiol. 2001;281(3):R760-R769.

14. Tamura $Y$, Watada $H$, Igarashi $Y$, et al. Short-term effects of dietary fat on intramyocellular lipid in sprinters and endurance runners. Metabolism. 2008;57(3):373-379.

15. Szczepaniak LS, Babcock EE, Schick F, et al. Measurement of intracellular triglyceride stores by $\mathrm{H}$ spectroscopy: validation in vivo. $\mathrm{Am} \mathrm{J}$ Physiol. 1999;276(5 pt 1):E977-E989.

16. Kiens B, Essen-Gustavsson B, Christensen NJ, Saltin B. Skeletal muscle substrate utilization during submaximal exercise in man: effect of endurance training. J Physiol. 1993;469(Sep):459-478.

17. Strojnik V, Apih T, Demsar F. Cross-section areas of calf muscles in athletes of different sports. J Sports Med Phys Fitness. 1995;35(1):25-30.

18. Nakagawa Y, Ratkevicius A, Mizuno M, Quistroff B. ATP economy of force maintenance in human tibialis anterior muscle. Med Sci Sports Exerc. 2005;37(6):937-943.

19. Bergh U, Thorstensson A, Sjdin B, Hulten B, Piehl K, Karlsson J. Maximal oxygen uptake and muscle fiber types in trained and untrained humans. Med Sci Sports. 1978;10(3):151-154.

20. Edgerton VR, Smith JL, Simpson DR. Muscle fibre type populations of human leg muscles. Histochem J. 1975;7(3):256-266.

21. Gregory CM, Vandenborne K, Dudley GA. Metabolic enzymes and phenotypic expression among human locomotor muscles. Muscle Nerve. 2001;24(3):387-393.

22. Farley CT, Ferris DP. Biomechanics of walking and running: center of mass movements to muscle action. Exerc Sport Sci Rev. 1998;26:253-286.

23. Oscai LB, Essig DA, Palmer WK. Lipase regulation of muscle triglyceride hydrolysis. J Appl Physiol. 1990;69(5):1571-1577.

24. Poirier P, Marcell T, Huey PU, et al. Increased intracellular triglyceride in $\mathrm{C}_{2} \mathrm{C}_{12}$ muscle cells transfected with human lipoprotein lipase. Biochem Biophys Res Commun. 2000;270(3):997-1001. 
25. Lithell H, Orlander J, Schele R, Sjodin B, Karlsson J. Changes in lipoprotein-lipase activity and lipid stores in human skeletal muscle with prolonged heavy exercise. Acta Physiol Scand. 1979;107(3):257-261.

26. Nikkilä EA, Taskinen MR, Rehunen S, Härkönen M. Lipoprotein lipase activity in adipose tissue and skeletal muscle of runners: relation to serum lipoproteins. Metabolism. 1978;27(11):1661-1671.

27. Hamilton MT, Etienne J, McClure WC, Pavey BS, Holloway AK. Role of local contractile activity and muscle fiber type on LPL regulation during exercise. Am J Physiol. 1998;275(6 pt 1):E1016-E1022.
28. Vock R, Weibel ER, Hoppeler H, Ordway G, Weber JM, Taylor CR. Design of the oxygen and substrate pathways. V. Structural basis of vascular substrate supply to muscle cells. J Exp Biol. 1996;199(pt 8): 1675-1688.

29. Howald H, Hoppeler H, Classen H, Mathieu O, Straub R. Influences of endurance training on the ultrastructural composition of the different muscle fiber types in humans. Pflugers Arch. 1985;403(4):369-376.

\section{Publish your work in this journal}

The Open Access Journal of Sports Medicine is an international, peer-reviewed, open access journal publishing original research, reports, reviews and commentaries on all areas of sports medicine. The journal is included on PubMed. The manuscript management system is completely online and includes a very quick and fair peer-review system. Visit http://www.dovepress.com/testimonials.php to read real quotes from published authors. 